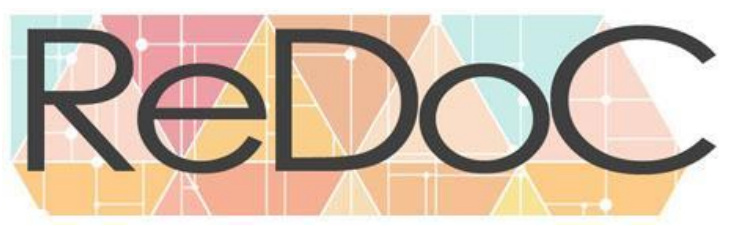

Revista Docência e Cibercultura

\title{
VERSOS E REVERSOS DE UMA GESTORA ESCOLAR EM TEMPOS DE ENSINO REMOTO
}

\author{
VERSES AND REVERSES OF A SCHOOL MANAGER IN TIMES OF REMOTE TEACHING
}

\section{VERSÍCULOS Y INVERSOS DE UN DIRECTOR ESCOLAR EN TIEMPOS DE ENSEÑANZA A DISTANCIA}

\author{
Joseane Lima Muniz ${ }^{1}$
}

\begin{abstract}
RESUMO
Diante do cenário pandêmico atual, a necessidade do ensino remoto fez com que os profissionais da educação se reinventassem. Nessa perspectiva, é necessário que os aprendizados adquiridos durante esse processo sejam registrados. Assim, a proposta deste manuscrito é relatar a experiência de uma coordenadora escolar à frente da gestão de uma escola da rede estadual do Ceará no ano de 2020. O trabalho baseou-se em uma pesquisa bibliográfica atrelada ao relato da prática da própria autora, o qual apresenta as dificuldades, os desafios e as superações, envolvendo os diferentes processos que são realidades na educação como a avaliação, o acompanhamento pedagógico e o desenvolvimento de projetos que acontecem no cotidiano escolar, e como tudo isso tornou-se possível acontecer fora dos muros da escola. De acordo com o relato foi possível perceber que a escola, já tão importante em tempos "normais", nesse momento de distanciamento foi ainda mais necessária, rompendo espaços físicos e estreitando vínculos.
\end{abstract}

PALAVRAS-CHAVE: Aprendizagem. Ensino Remoto. Tecnologia.

\section{ABSTRACT}

Faced with the current pandemic scenario, the need for remote learning has made education professionals reinvent themselves. From this perspective, it is necessary that the lessons learned during this process are recorded. Thus, the purpose of this manuscript is to report the experience of a school coordinator in charge of the management of a school in the state network of Ceará in 2020. The work was based on a bibliographical research linked to the report of the author's own practice, the which presents the difficulties, challenges and overcomings, involving the different processes that are realities in education, such as assessment, pedagogical monitoring and the development of projects that take place in everyday school life, and how all this became possible to happen outside the walls from school. According to the report, it was possible to see that the school, already so important in "normal" times, was even more necessary in this moment of distancing, breaking physical spaces and strengthening bonds.

Submetido em: 01/05/2021 - Aceito em: 01/12/2021 - Publicado em: 17/12/2021

${ }^{1}$ Mestre em Tecnologia de Alimentos (IFCE), Especialista em Educação Profissional, Científica e Tecnológica (IFCE), Especialista em Gestão Escolar (UFC), Licenciada em Química (UECE), Tecnóloga em Alimentos (CENTEC), Docente da Secretaria de Educação do Estado do Ceará (SEDUC), Coordenadora Escolar da EEM Raul Barbosa, Formadora do Programa de Fortalecimento da Atuação do Coordenador Escolar (FACE). 


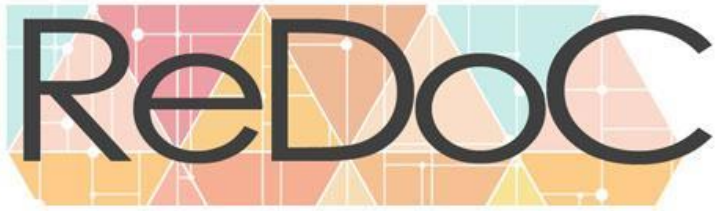

Revista Docência e Cibercultura

KEYWORDS: Learning. Remote Teaching. Technology.

\section{RESUMEN}

Ante el actual escenario pandémico, la necesidad del aprendizaje a distancia ha hecho que los profesionales de la educación se reinventen. Desde esta perspectiva, es necesario que se registren las lecciones aprendidas durante este proceso. Así, el propósito de este manuscrito es relatar la experiencia de un coordinador escolar a cargo de la gestión de un colegio en la red estatal de Ceará en 2020. El trabajo se basó en una investigación bibliográfica vinculada al informe de la propia práctica del autor el cual presenta las dificultades, desafíos y superaciones, involucrando los diferentes procesos que son realidades en la educación, como la evaluación, el seguimiento pedagógico y el desarrollo de proyectos que se dan en la vida escolar cotidiana, y cómo todo esto se hizo posible que suceda fuera de la escuela. Según el informe, se pudo constatar que la escuela, ya tan importante en tiempos "normales", era aún más necesaria en este momento de distanciamiento, ruptura de espacios físicos y estrechamiento de vínculos.

PALABRAS CLAVE: Aprendiendo. Enseñanza remota. Tecnología.

\section{INTRODUÇÃO}

Recentemente, eu li a seguinte frase de Walter Payton: "quando você é bom em algo, você fala para todo mundo. Quando você é ótimo, todo mundo te fala." Para iniciar esse texto, vamos nos deter na primeira parte desta frase. Eu me achava boa em algo, e esse algo era a tecnologia.

Eu sempre gostei de estudar, de aprender, e para isso me lancei no universo da informática como ferramenta de suporte aos meus estudos. É bem verdade que nunca cursei nada específico na área, porém, diante da dedicação autodidata, considerava meus conhecimentos até acima da normalidade, suprindo as minhas demandas pessoais e profissionais; visto que, além do trabalho com diversos sistemas, editores de textos, planilhas e apresentações, também me dedicava à elaboração de artes gráficas. Sempre fui adepta também das formações continuadas a distância, tendo feito, inclusive, duas pós graduações lato senso nessa modalidade.

Contudo, em 19 de março de 2020, minha vida profissional e, porque não dizer pessoal, sofreu um reverso quando, diante do cenário de crescimento exponencial de contágio pelo COVID19, o Governo do Ceará decretou isolamento social em todo estado, orientando o fechamento dos estabelecimentos públicos e privados de acordo com o decreto 33.519, de 19 de março de 2020. Fui mandada para casa; para trabalhar em casa. E aí? Eu trabalhava em uma escola, escolas são formadas por pessoas, como vou continuar a trabalhar sem o contato com as 


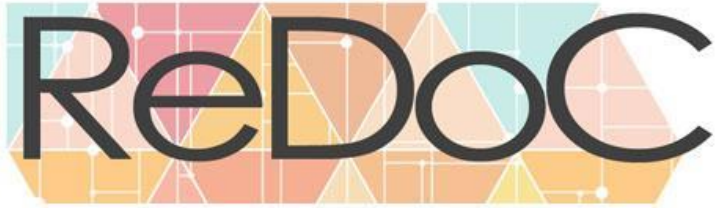

\section{Revista Docência e Cibercultura}

pessoas? Como vou acompanhar os alunos? Como vou coordenar os professores? Meu Deus! E as aulas expositivas/práticas? E as avaliações? E o projeto Diretor de Turma ${ }^{2}$, que é justamente o trabalho "próximo" ao aluno, como vai ser? Como vou fazer para conduzir meu trabalho com a vida pessoal em um mesmo espaço?

Com essas perguntas na cabeça e com a necessidade de apresentar minha experiência durante os primeiros meses de ensino remoto, este trabalho tem como objetivo principal refletir sobre os desafios e os aprendizados enfrentados por gestores, em particular, a autora em questão, na implementação do ensino remoto em uma escola estadual do Ceará imposto pelo contexto pandêmico do COVID-19. Espera-se também com o trabalho, apontar os diversos recursos humanos e tecnológicos disponíveis para apoiar a realidade das aulas remotas bem como analisar a conjuntura que levou ao enfrentamento dos problemas gerados pelo distanciamento do espaço escolar por parte dos alunos e profissionais da educação.

As dificuldades enfrentadas nos diversos níveis pelos educadores em todo Brasil tornam este relato relevante na premissa social, pois ele traz o compartilhamento da realidade educacional vivenciada por mim, levando o leitor a meditar até que ponto o isolamento impactou em sua vida.

Em termos profissionais, a experiência torna clara os desafios enfrentados pelos docentes diante da mudança brusca de metodologias utilizadas até então por professores somente voltados para o ensino presencial. Também é possível analisar o percurso seguido pela equipe escolar na superação dos desafios; sendo assim, uma leitura importante para aos que estão atuando na linha de frente da educação no contexto de ensino remoto.

\footnotetext{
2 De acordo com o site da Secretaria de Educação do Estado do Ceará, o Projeto Professor Diretor de Tuma está vigente desde 2008. O mesmo propõe que o professor, independentemente de sua área de conhecimento, responsabilize-se por uma determinada turma, cabendo-lhe conhecer os estudantes individualmente, para atendêlos em suas necessidades. Além disso, são atribuições do professor diretor de turma (PDT) a mediação das relações entre a sua turma e os demais segmentos da comunidade escolar, bem como o trabalho de formação cidadã e desenvolvimento de competências socioemocionais, junto aos seus estudantes.
} 


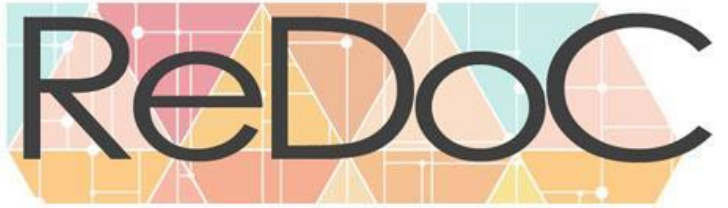

\section{Revista Docência e Cibercultura}

Assim, vejo a necessidade de apresentar este trabalho nas páginas seguintes com a proposta de mostrar o desbravamento deste que foi um dos momentos mais transformadores vivido pela área da educação até os dias de hoje.

\section{UMA SALA DE AULA FORA DA ESCOLA}

Partindo da naturalização da ideia de que os processos de escolarização não podem ser interrompidos, ao contrário das atividades produtivas, Saraiva, Traversini e Lockmann (2020) afirmam que a indústria, comércio e serviços pararam, mas as escolas não podem parar com a justificativa de que devem funcionar, mesmo que de modo precário, para assim, evitar danos maiores.

Dessa forma, diante do cenário de distanciamento imposto pela pandemia, bem como com a orientação da Secretaria de Educação do Estado do Ceará, que via a necessidade de manter o contato com o aluno, a gestão escolar da EEM Raul Barbosa, a qual faço parte, tomou a decisão de manter a rotina de atividades escolares usando o aplicativo de mensagens instantâneas, Whatsapp, enviando, via grupos formados neste aplicativo, atividades de acordo com o horário de aulas estabelecido ainda para o ensino presencial. Santos e Santos (2021, p. 5), Farias (2020), e Martins e Parreira Júnior (2020) corroboram com a realidades apresentada neste trabalho afirmando que o uso do WhatsApp tornou-se uma maneira de aproximar alunos e professores proporcionando trocas de materiais pedagógicos, assuntos, atividades, entre outros. Em muitos contextos escolares, devido a situação pandêmica e a necessidade do isolamento social, foram formados diversos grupos de estudos com diferentes turmas. Contudo, adesão do alunado foi tímida, visto que existia sempre a prerrogativa esperançosa de um retorno eminente, cujas atividades poderiam ser entregues nesse momento.

Cada professor abraçou a ação e fez uso de sua estratégia. Eu, enquanto coordenação, tentava está em todos os grupos, abrindo cada atividade, cada vídeo-aula, tentando acompanhar quem e quantos davam, devolutivas. E, claro, rapidamente eu percebi que isso seria impossível! 
Em face desse universo novo, em que a experiência e o conhecimento que já tínhamos sobre como fazer educação no chão da escola foram colocados à prova, Pádua e França-Carvalho (2020, p. 2) relatam a real situação em que se encontra o coordenador pedagógico nesse cenário.

Situado nessa conjuntura de "sobrevivência", o coordenador pedagógico, tem se redescoberto diante de situações antes não vivenciadas e tampouco discutidas na graduação em licenciatura. Diante desse contexto de incertezas e aprendizagem pelo acerto e erro, que propomos refletir as ações empreendidas por esse profissional em tempo de pandemia, a partir das experiências educativas desenvolvidas enquanto ações inerentes a função.

Diante da afirmação, e compreendendo que a função busca constantemente uma identidade embora diante de um grande número de demandas, o coordenador pedagógico tem que se ressignificar para manter a equipe envolvida no processo educacional mesmo a distância.

Atestando o que Martins, Andrade e Zandavalli (2020, p. 5) afirmaram em seu trabalho, a multiplicidade de atribuições demanda tempo e causa dificuldades aos coordenadores, que acabam não executando todas as tarefas com a qualidade desejada, pois também têm dificuldades em priorizá-las. Comprovei a afirmação de forma prática diante da dificuldade de acompanhar as ações dos docentes coordenados por mim, bem como as demais demandas que são responsabilidade da coordenação pedagógica.

Libâneo (2004) menciona que a coordenação pedagógica nada mais é do que um elo mediador entre o fazer pedagógico e o docente. Ao coordenador, cabe promover a cultura do diálogo docente como o objetivo de traçar planos na busca de soluções, no sentido de melhorar a práxis pedagógica, tão essencial para uma aprendizagem de sucesso.

Contudo, o contexto de isolamento inquietava-me, visto que a troca de experiências tão importante para o crescimento do trabalho docente, bem como a diversificação de práticas e o êxito na implantação destas nas salas de aula com os alunos estavam deveras comprometidas.

Segundo Santos (2020), o trabalho colaborativo e interdisciplinar, organizado pelo coordenador pedagógico entre professores facilita a contextualização do ensino a situações reais do estudante. Por se tratar de uma situação vivenciada no momento, ainda não se sabe quais serão todos os impactos sociais e pedagógicos que o contexto da pandemia provocará, porém 


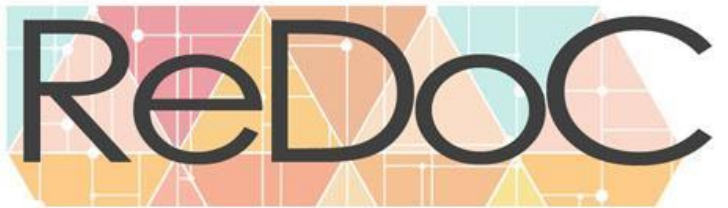

\section{Revista Docência e Cibercultura}

acredita-se que a condução das aulas remotas amenize as lacunas deixadas pela ausência total do convívio escolar.

E é por entender que coordenar uma escola é ser elo, é estar em contato, foi que me vi na necessidade de ir além e de buscar nas tecnologias os recursos para manter o contato entre a equipe.

\section{ACOMPANHAMENTO PEDAGÓGICO PELA TELA: QUEM SABE FAZ AO VIVO!}

O uso das vídeo-conferências foi necessário. Mas, como assim? Por que eu nunca tinha ouvido falar dessa ferramenta: Google Meet?

Diante da necessidade de conversar com o grupo de professores de uma única vez, de decidir, de orientar, de ouvir depoimentos, de projetar imagens e informações visíveis a todos, passamos a usar a vídeo-conferência. No entanto, antes foi necessário aprender a manuseá-la. E na escola coube a mim esta função. Tentei pedir ajuda, assisti a tutoriais e montei a primeira... uns conseguiram entrar; porém, outros não. Por que isso aconteceu? Montei a segunda... não consegui exibir uma apresentação. Montei a terceira... deu certo! E assim, até hoje, usamos esse aplicativo da google para conversarmos em grupo, para planejarmos, para realizarmos formações. E seguindo o mesmo ritmo, os professores também iniciaram o uso desse recurso em suas aulas, com seus alunos, tornando-as mais interativas.

Corroborando com a minha realidade, enquanto coordenação pedagógica, Silva e Machado (2021, p. 9) mostraram que foi uma realidade comum no início da pandemia.

Onde são poucos os professores que tinham como hábito utilizar as tecnologias como parte integrante de suas atividades diárias, pois preparar uma aula remota é bem diferente da prática presencial, necessitando uma outra dinâmica de interação com os alunos e diferentes formas de comunicação com os familiares, criando uma rotina de estudos que muitas vezes, torna-se mais pesada pelo aluno necessitar de auxílio e estar em um espaço que normalmente era priorizado com atividades de descanso e de lazer. 


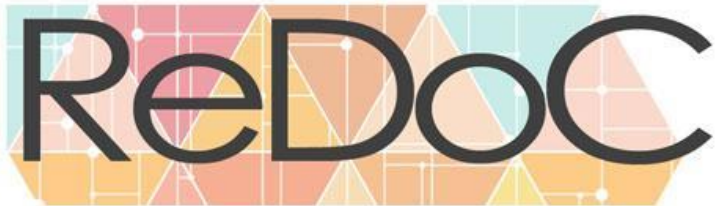

\section{Revista Docência e Cibercultura}

Contudo, Bouchard, em 2000, já afirmava que as tecnologias em uso possibilitam níveis de diálogo de acordo com suas características estruturais, as quais interferem na distância transacional e, consequentemente, nas possibilidades interativas. Assim, as aulas tornaram-se mais atrativas, mais "parecidas" com aulas normais.

Em um contexto de isolamento vivenciado pela educação brasileira, Teixeira e Nascimento (2021, p. 54) comentam que o mundo parou diante da pandemia, e a escola abriu suas janelas para um ensino cada vez mais moderno, onde se produz e reproduz informações, de forma que o conhecimento se modifica, circula e se atualiza em tempo real e em diversas interfaces, sendo possível “digitalizar sons, imagens, gráficos, textos, enfim uma infinidade de informações”.

Assim, corroborando com Teixeira e Nascimento (2021), Vale (2020) aponta que o uso do Google Meet, como ferramenta de ensino e aprendizagem, possibilita, além das trocas síncronas entre os participantes, uma vasta interatividade promovendo atividades colaborativas, utilização de quis e gamificações, dentre outros.

Marinho et al. (2020) também mencionam alguns pontos relevantes para o uso do Google Meet, sendo uma ferramenta versátil que atende de forma satisfatória a diversas atividades e cursos que possuem distintas necessidades, como a extensão Grid View, em que é possível ver todos os participantes na tela de uma só vez, o compartilhamento de tela que permite ao professor usar um documento de texto como lousa digital, a funcionalidade de gravação das aulas, a capacidade de muitos participantes em uma única chamada.

Contudo, Marinho et al (2020) também analisa que o Google Meet possui algumas limitações, como a impossibilidade de o administrador desativar a câmera dos participantes. Além disso, para participar da vídeo-chamada, o participante não precisa estar conectado a seu e-mail; de forma que é possível que pessoas mal intencionadas consigam, por meio do link de acesso, adentrar a sala e tumultuar o andamento do evento.

Atentos aos pontos mostrados pelos autores citados, vivenciamos todas essas particularidades, visto o uso rotineiro da ferramenta. 


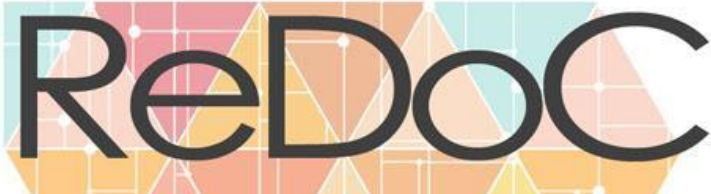

\section{Revista Docência e Cibercultura}

\section{OS NÚMEROS COMO ALIADOS}

É bem verdade que a conjuntura atual da educação, de certa forma, não valoriza mais os números quando se fala em desmassificação do ensino, análise do aluno como individuo único, como protagonista de seu processo de ensino aprendizagem.

Mas antes de analisar o aluno individualmente, a realidade do ensino remoto me ensinou que era necessário conhecer os números desse novo tipo de ensino.

Quantos alunos tinham acesso? Quantos participavam das atividades síncronas? Quantos das assíncronas? Quantos estavam realizando as atividades impressas? Quantos, mesmo com acesso, se sentiam totalmente desmotivados a participar do ensino remoto? Como estava a resposta dos alunos às avaliações remotas?

Que tipo de coordenadora eu seria se não tivesse a par desses números? Enquanto educadora, eu compreendo que, por trás do número, existe o aluno; existe a razão para aquele número, existe a resposta socioeconômica ou socioemocional, existe a prática que deu (ou não) certo, existe um professor que trabalha dentro das premissas do projeto professor diretor de turma fazendo a diferença na busca ativa do aluno, no combate à evasão escolar, no apoio socioemocional ao estudante...existe alguém. Para esse acompanhamento, o recurso tecnológico das planilhas de excel, em parceria com o Google Drive, foram essenciais para manter registros atualizados e tomadas de decisões mais assertivas em tempo hábil.

Com relação ao Google Drive, este é visto por mim e pelos professores como a principal ferramenta de arquivamento, bem como pela facilidade de compartilhamento de arquivos com outros usuários.

Siqueira et al. (2020) mencionam como o Google Drive tem aplicações voltadas para armazenamento de informações que contribuem para praticidade do trabalho do professor. 


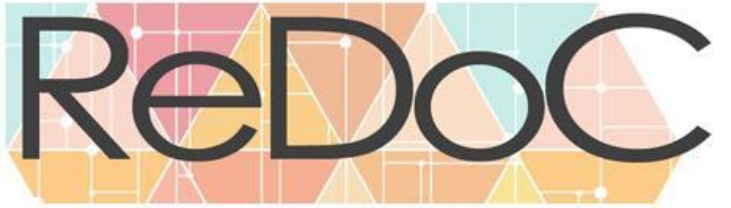

\section{Revista Docência e Cibercultura}

Todos os materiais postados pelo professor na plataforma Google Classroom ficam salvos no Google Drive, na pasta da turma, garantindo assim que os alunos não percam aquele material. Provas e testes podem ser realizados pelos alunos no Google Forms que garante ao professor uma forma fácil e rápida de obter os resultados através de correção automática, sendo que o questionário com as respostas dos alunos também fica arquivado no Google Drive.

Com relação ao excel, Garofalo (2018) afirma que o uso do mesmo nos diversos setores da vida moderna, torna prática muitas ações do cotidiano. Para alguns, pode ser desafiador; para outros, é dinâmico e capaz de despertar o interesse e o crescimento em diversas situações do nosso diaa-dia.

Partindo desse ponto, na área da educação, o programa permite inúmeras possibilidades de uso em diferentes níveis e ciclos de aprendizagem. A coordenação pedagógica, que tem como uma das principais ações o acompanhamento aos resultados das aprendizagens dos alunos, tem como ferramenta importante as planilhas; visto que, ainda segundo Garofalo (2018), elas possibilitam usufruir de recursos que tornam o processo de aprendizado mais produtivo, fomentando a exposição dos conteúdos e organização da rotina escolar ao produzir materiais didáticos.

E, durante o ano de 2020, eu analisei muitas situações dentro do meu contexto escolar que iniciaram com um número em uma planilha.

\section{AVALIANDO SEM MEDIR DISTÂNCIA}

A questão da avaliação, mesmo em tempos “ditos normais", já abria precedentes para intensos debates; imagine, caro leitor, em tempos de ensino remoto!

Monteiro (2020, p. 17), em seu trabalho, traz à tona as dificuldades da avaliação em tempos de ensino remoto, em que o mesmo afirma que 


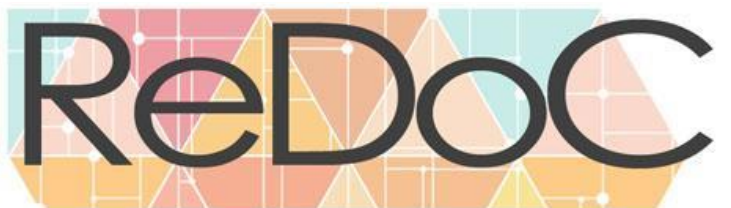

\section{Revista Docência e Cibercultura}

considerando as dificuldades comuns de implementação do fazer pedagógico que passou a exigir ainda mais a competência criativa por parte do educador, uma questão, de maneira especial, tem sido provocativa e conflitante para muitos professores, presos a um processo avaliatório que sentencia, classifica e expressa retorno por meio de números que quantificam o quanto cada aluno vale nesse processo de aquisição e descarte de conhecimento. Obviamente que a iniciativa facilita o olhar do professor que limita seu trabalho à tradução numérica do que o aluno é capaz de oferecer, ignorando, sobremaneira, a competência, os resultados, as dificuldades e a aprendizagem do informado.

As discussões conflituavam em torno das inúmeras possibilidades do aluno "colar" em sua avaliação e a tão importante "nota" não retratar a aprendizagem real do educando.

Não vai dar certo! Eles vão colar! Não vão nem ler direito! Outra pessoa irá fazer por ele! Essas foram algumas das muitas frases que escutei dos professores quando lançamos a proposta de avaliarmos os nossos alunos. Foram muitas vídeo-conferências em que inicialmente flexibilizamos a metodologia de avaliar.

Marquesin e Benevides (2011) afirmam que a presença da cola mostra que o aluno precisa aprender a aprender. O professor, como mediador do conhecimento, deve partir dele essa reflexão sobre a necessidade do aluno ir além da nota, e sim, buscar o conhecimento e aplicálo.

Assim, ainda citando Monteiro (2020, p. 20), é imprescindível que o repensar sobre avaliação em tempo de ensino remoto seja uma premissa importante para o professor, sendo que o mesmo deve ser reflexivo com relação ao processo. Dessa forma, o autor menciona que

Grandes são os questionamentos e dúvidas acerca da volúpia que emerge do professor em tempos de "dar nota". Todavia, em tempos de ensino remoto, parece ser uma construção mental equivocada por parte do docente, quando parece querer sustentar a existência de um mundo feliz onde todos os envolvidos no processo encontram-se alinhados e em condições de igualdade tecnológica para aprender, desmentindo o conceito real de que que todos possuem um tempo psíquico e intelectivo de aprendizagem

A vivência do ensino remoto mostrou diversos tipos de aluno; e estes, encaixando-se em diversas formas de avaliação. Antes, porém, sinto-me na necessidade de apresentar a evolução em termos reflexivos com relação ao ato de avaliar na escola onde trabalho.

Muitas coisas mudaram! Atitudes, posturas, falas e até mesmo sentimentos! E o processo avaliativo, antes classificatório-somativo, tornou-se em sua essência, formativo. O aluno 


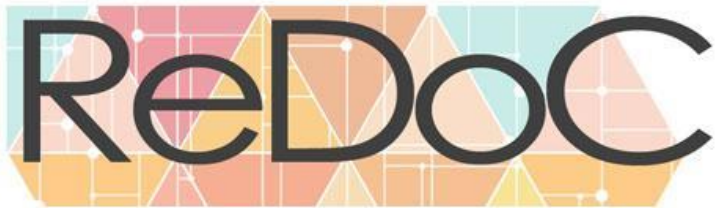

\section{Revista Docência e Cibercultura}

passou a ser avaliado pelo processo que o mesmo protagoniza, sendo que a construção do conhecimento se revelou em suas produções das mais diversas atividades.

Segundo Tinoca e Oliveira (2013), a forma avaliativa formativa gera um leque de possibilidades que, durante o ensino remoto, tiveram ampliação no seu repertório devido à infinidade de plataformas ancoradas no ambiente online. A ideia do virtual proporciona além do interesse por parte do aluno, a visão do progresso por parte do professor.

Dessa forma, na minha realidade escolar, pude constatar que a criatividade e a empatia dos professores se sobressaíram no processo. Sim, eles se superaram! As Artes realizaram um festival; a Biologia apresentou várias vídeo-aulas confeccionadas pelos alunos; a Matemática fez avaliação individual por vídeo-chamada; a Física avaliou por experimentação; o Português, por produções coletivas; e assim se deu nosso processo inicial de avaliação. Por fim, a escola hoje mantém um leque de avaliações parciais a cargo da forma como o professor considera prudente. Não podemos deixar de lado o que hoje já é rotineiro, os formulários google que usamos para fechar os períodos letivos (bimestres).

Gotti (2020, p. 2) aponta em seu estudo a relevância de um processo baseado em uma avaliação formativa, no sentido de diversificar a prática e amenizar as perdas, resultado da suspensão das aulas presenciais.

As redes de ensino e escolas que conseguiram monitorar, por meio de avaliações formativas, a qualidade do vínculo educacional ao longo da quarentena, terão informações preciosas para melhor avaliar as condições de retorno. Isso porque, repise-se, esse tipo de avaliação é fundamental para a adoção de estratégias com foco nas lacunas pedagógicas do estudante e, se bem feita e utilizada, tem potencial de contribuir para uma melhor aprendizagem ao propiciar elementos para correções de distorções, garantindo mais equidade.

Sobre a equidade no processo avaliativo, a pandemia nos ensinou que a desmassificação dos alunos é o meio para realizarmos uma avaliação equitativa, no sentido de entender as deficiências, inclusive, analisando os motivos que nesse momento de aulas remotas podem ser constatados, os quais muitos são de origem social. 


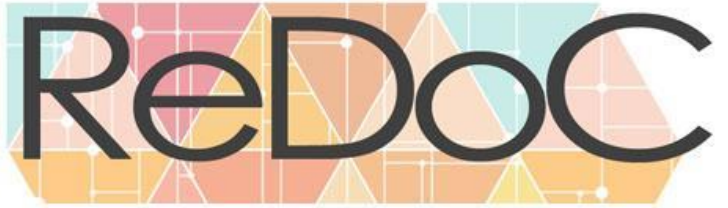

\section{Revista Docência e Cibercultura}

Apoiando a ideia de que o professor pode e deve se ancorar em seus conhecimentos prévios sobre a realidade do grupo a ser avaliado, Paschoalino, Ramalho e Queiroz (2020, p. 125) afirmam que

o professor é demandado a ampliar os seus conhecimentos teóricos sobre a temática de avaliar e seus condicionantes. Nesse processo, ao ser instaurado dois movimentos se intercambiam e se superpõe de temáticas sobre a avaliação. Em um deles é a aquisição individual de cada professor sobre a temática da avaliação, em outro movimento, se expressa na formação na construção e/ou ressignificação dos professores envolvidos em reflexão sobre as suas próprias experiências e saberes.

Todos esses recursos culminam em um processo de avaliação formativa que vem crescendo e melhorando a qualidade avaliativa a cada ciclo.

\section{ESPALHADOS, MAS JUNTOS: A ESSENCIALIDADE DO PROFESSOR DIRETOR DE}

\section{TURMA}

A meu ver, nenhum projeto, a nível de Secretaria de Educação do Estado do Ceará, foi tão essencial nesse contexto de aulas remotas como o Projeto Professor Diretor de Turma.

De acordo com Costa e Magalhães Júnior (2018), o diretor de turma é um professor que, além de lecionar a sua disciplina específica, também exerce o cargo de Diretor de Turma. Encarregase da aproximação entre alunos, professores e demais segmentos da comunidade escolar; bem como da promoção de um clima favorável à aprendizagem e aproximação e abertura às famílias.

Partindo da afirmação acima e da necessidade de vínculos, esse professor assumiu nesse contexto pandêmico a missão de ajudar na manutenção do elo aluno-escola. $\mathrm{O}$ termo busca ativa foi amplamente utilizado para nomear todas as ações de contato com o aluno, sejam elas de motivação, para que o aluno realize as atividades; seja para conversar sobre os anseios dos alunos nesse período. E em nossas escolas esse professor fez muita diferença. 


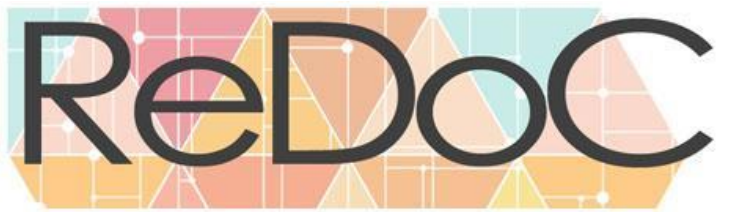

\title{
Revista Docência e Cibercultura
}

É importante destacar que as atribuições mencionadas por Costa e Magalhães Júnior (2018) são apresentadas de forma bastante resumida. Já Tavares (2011, p.452-453), aponta uma visão mais discorrida sobre as inúmeras atribuições deste professor no contexto escolar.

\begin{abstract}
Fundamentando-se a matriz do projeto em Portugal, o DT tem por competências e deveres: - esclarecer os alunos acerca das funções do diretor de turma e informá-los, assim como aos encarregados de educação, do seu horário de atendimento; - estimular a participação do aluno na vida da escola e da comunidade; - promover a eleição do delegado e subdelegado de turma e fornecer o nome destes ao núcleo gestor, a fim de ser elaborado o caderno para a eleição dos representantes dos alunos junto ao conselho pedagógico; - criar e desenvolver um diálogo aberto com a turma; - facilitar aos encarregados de educação a comunicação com a escola, mantendo-os informados e esclarecidos, quer por meio de reuniões, quer por intermédio de correspondência e dos contatos semanais; organizar e garantir a funcionalidade do dossiê de turma; - verificar semanalmente as faltas dos alunos nas diferentes disciplinas, relevar as devidamente justificadas e informar, por escrito, os encarregados de educação sempre que o número de faltas dos respectivos educandos atinja metade ou o total do limite legalmente estabelecido, elucidando-os das consequências caso esse limite seja ultrapassado; - estar atento às informações dadas pelos professores e comunicá-las aos encarregados de educação, sempre que a situação do aluno o aconselhar; exigir aos professores da turma que comuniquem, sempre e por escrito, as infracções disciplinares cometidas pelos alunos que impliquem falta de presença; - verificar o registro das datas de marcação das fichas de avaliação somativa, de forma a que não seja marcada mais do que uma prova de avaliação no mesmo dia; - presidir às reuniões de conselho de turma, que deverão ser previamente preparadas; - apresentar ao núcleo gestor um relatório crítico anual do trabalho desenvolvido; - garantir uma informação atualizada e esclarecer os alunos acerca da assiduidade, pontualidade, regime de faltas, regras internas da escola, disciplina e regras de procedimento disciplinar, importância e funções do delegado e subdelegado de turma, avaliação e orientação escolar.
\end{abstract}

Assim, analisando o repertório de atividades desenvolvidas pelo Professor Diretor de Tuma, o qual vivencio diariamente, afirmo que, quem desenvolve essa função ama o que faz e tem pela educação dos nossos jovens um grande compromisso.

Dessa forma, na minha análise sobre os Professores Diretores de Turma, com os quais convivo, mostram que eles foram os atores principais desse ensino remoto (pelo menos na minha visão de gestora e, claro, reportando-me à realidade da minha escola). Eles se apresentaram como o maior elo entre escola e aluno durante esta pandemia. Eles foram a "fibra ótica" que não deixou ninguém (ou quase ninguém) se desconectar. Conseguiram, no ensino remoto, de forma substancial manter todas as atividades do projeto diretor de turma, que, antes eram realizadas presencialmente, elevando de forma significativa a qualidade das mesmas, partindo do elo socioemocional construído com o aluno.

Paschoalino, Ramalho e Queiroz (2020, p. 118) afirmam a grande importância que tem a relação entre professor e aluno. A coparticipação efetiva na construção do conhecimento e a 


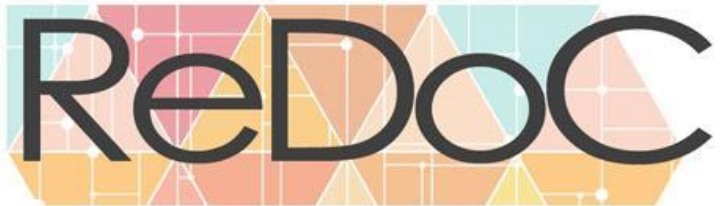

\section{Revista Docência e Cibercultura}

aprendizagem significativa, segundo os autores, devem ser marcadas pelo respeito e afetividade e proporcionar novos aprendizados a partir de desequilíbrios a serem vencidos.

Entretanto, cabe aqui ainda mencionar que os Professores Diretores de Turma sofrem... nós sofremos! Sofremos com o aluno que some e passamos muito tempo sem notícias; sofremos com os que não têm acesso, com os desmotivados e com as inúmeras demandas que o tempo não permite que se atenda em $100 \%$.

\section{CONSIDERAÇÕES FINAIS/CONCLUSÃO}

Voltando à frase de Payton, especificamente para a segunda parte: “...Quando você é ótimo, todo mundo te fala." Não sou ótima, mas estou conseguindo superar, conseguindo aprender, conseguindo mobilizar, conseguindo motivar... e isso me dá fôlego para seguir. É possível compreender que a tecnologia está totalmente a nosso favor, que é só necessário desbravá-la, estudá-la, usá-la. Como gestora, vejo que o principal problema ainda está em chegar ao aluno, em mantê-lo focado, em dar sentido ao processo (a distância) de ensino aprendizagem, de dar ao aluno um projeto de vida para além da pandemia. Leio a respeito, trago sugestões, converso com professores e diretamente com os alunos, acho que estamos no caminho. Nunca ficou tão claro para mim que a educação é o caminho.

\section{REFERÊNCIAS}

BOUCHARD, Paul. Autonomia e distância transacional na formação a distância. In:

ALAVA, S. (Org.). Ciberespaço e formações abertas. Porto Alegre: Artmed, 2000. cap. 3.

CEARÁ. Decreto no 33.519, de 19 de março de 2020. Intensifica as medidas para enfrentamento da infecção humana pelo novo coronavírus. Diário Oficial do Estado do Ceará, Poder Executivo, Fortaleza, série 3, ano 12, n. 56. Disponível em: https://www.ceara.gov.br/decretos-do-governo-do-ceara-com-acoes-contra-o-coronavirus Acesso em: 01 de maio 2021 


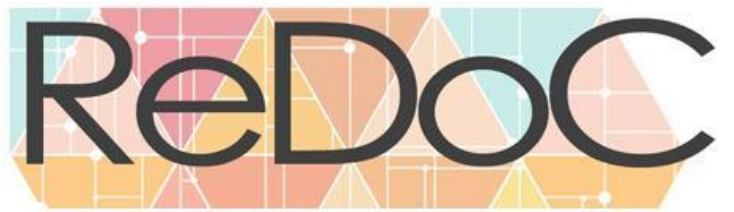

\section{Revista Docência e Cibercultura}

COSTA, G. P.; MAGALHÃES JUNIOR, A. G. O "projeto professor diretor de turma" nas escolas de ensino médio do Ceará como possibilidade de promoção do direito humano à educação. Revista Expressão Católica, Quixadá, v. 7, n. 1, Jan - Jun, 2018.

FARIAS, D. F. Um relato de experiência: o uso do whatsapp no ensino de fisica durante o isolamento social no Colégio Estadual do Campo de Campo Formoso (Anexo Tuiutiba).

Estudos IAT, Salvador, v.5, n.3, p. 307-317, out., 2020. Disponível em:

http://estudosiat.sec.ba.gov.br. Acesso em 29 ago 2021

GAROFALO, Débora. Professor, use mais (e melhor) o Excel em suas aulas. Portal Revista Nova Escola [05/09/2018]. Disponível em: https://novaescola.org.br/conteudo/12535/ professor-use-mais-e-melhor-o-excel-em-suas-aulas. Acesso em 31 de jul. 2021.

GOTTI, Alessandra. Como avaliar em tempos de pandemia? Portal Revista Nova Escola, [30/06/2020]. Disponível em: https://novaescola.org.br/conteudo/19435/como-avaliar-emtempos-de-pandemia. Acesso em 30 de jul. 2021.

LIBÂNEO, José Carlos; Organização e Gestão da Escola: teoria e prática. Goiânia: Alternativa, 2004.

PAYTON, Walter. [Ano ?]. Disponível em: https://www.facebook.com/EscritoNoLivro QueEuLi/posts/1054059007966872/. Acesso em: 07 mar. 2021.

MARINHO, T. B.; LEMOS, R. S.; NUNES, A. L. B.; SILVA, A. C. B.; CAVALCANTE, D. da $\mathrm{N}$ e S. Viabilidade do google meet em aulas remotas. In: CONGRESSO BRASILEIRO DE EDUCAÇÃO EM ENGENHARIA, 48., 2020, Caxias do Sul, Anais[...] Caxias do Sul: Universidade de Caxias do Sul, 2020, p. 1-10.

MARQUESIN, D. F.; BENEVIDES, C. R. Avaliação da aprendizagem no ensino superior: reflexões sobre a cola. Revista da Educação, Santa Maria, v. 14, n. 18, p. 9-18, 2011.

MARTINS, A. F. M.; ANDRADE, A.B. dos S. ZANDAVALLI, C.B. Desafios da coordenação pedagógica em Mato Grosso do Sul em tempos de trabalho remoto. In: INTEGRA EAD, 1., 2020, Campo Grande. Anais[...] Campo Grande: UFMS, 2020. p. 1-15.

MARTINS, F. A.; PARREIRA JUNIOR, W. M. Caminhos alternativos de aula remota utilizando recursos digitais. In: SEMINÁRIO MINEIRO DE EDUCAÇÃO INTEGRAL, 3., 2020, Uberaba, Anais [...] Uberaba: Universidade Federal do Triângulo Mineiro, 2020, p. 1-

MONTEIRO, Márcio de Oliveira. Avaliação em tempos de pandemia: uma abordagem holística do processo. Revista Transformar, São José de Itaperuna, ano. 14, Edição Especial, mai./ago. p. 6-27, 2020. 


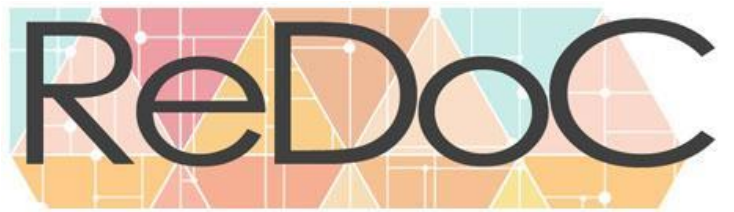

\section{Revista Docência e Cibercultura}

PÁDUA, C. A. L. de O.; FRANÇA-CARVALHO, A. D. Ações desenvolvidas pelo coordenador pedagógico em tempo de pandemia: um relato de experiência. Holos, Natal, ano 36, v.5, e.11393, p. 1-12, 2020.

PASCHOALINO, J. B. DE Q.; RAMALHO, M. L.; QUEIROZ.; V. C. B. de. Trabalho docente: o desafio de reinventar a avaliação em tempos de pandemia. Revista Labor, Fortaleza, v. 1, n. 23, p. 113-130, 2020. Disponível em:

http://www.periodicos.ufc.br/labor/index ISBN: 1983-5000 113. Acesso em: 07 mar. 2021.

SANTOS, Michele Serafim. O trabalho do coordenador pedagógico em tempos de pandemia: relatos de uma articuladora sobre atividades remotas. In: INTEGRA EAD, 1., 2020, Campo Grande. Anais[...] Campo Grande: UFMS, 2020. p. 1-8.

SANTOS, E. C. dos; SANTOS, R. F. F. dos. WhatsApp como ferramenta de comunicação entre professores e alunos em tempos de aulas remotas: uso e suas implicações. In:

SÍMPOSIO INTERNACIONAL DE COMUNIÇÃO, 10., 2021, Aracaju, Ânais [...] Aracaju: Universidade Tiradentes, 2021, p. 1-14.

SARAIVA, K.; TRAVERSINO, C.; LOCKMANN, K. A educação em tempos de COVID19: ensino remoto e exaustão docente. Práxis Educativa, Ponta Grossa, v. 15, e2016289, p. 1-24, 2020 Disponível em: <https://www.revistas2.uepg.br/index.php/praxiseducativa> Acesso em: 07 mar. 2021.

SILVA, S. R. T de F.; MACHADO, E. Reflexões sobre a educação em época de crise, o impacto da pandemia: a partir da visão de professores da educação básica. In:

CONGRESSO INTERNACIONAL DE PEDAGOGIA, 86., 2021, La Habana. Anais eletrônicos[...] La Habana: Ministerio de Educación de la República de Cuba, 2021. Disponível em: https://www.pedagogiacuba.com/simposio/formacion-integral-de-ninos- adolescentes-yjovenes-la-prevencion-y-mitigacion-de-multiriesgos-de-desastres-naturales-tecnologicos-ysanitarios/. Acesso em: 31 jul. 2021.

SIQUEIRA, M. L. G.; ALTINO FILHO, H. V.; CRUZ, T. O. F. da; NEIVA, E. M. S. da; ASSUNÇÃO, B. R. Plataformas educativas nas aulas remotas durante a pandemia causada pelo covid-19. Noite Acadêmica, Recife, v. 1, p. 1-9, 2021.

TAVARES, Andrevaldo Glaidson Pereira. O professor diretor de turma como mediador do processo de ensino-aprendizagem. Revista Pedagógica, Chapecó, Ano 14, n. 27, v. 02 jul./dez. 2011. 


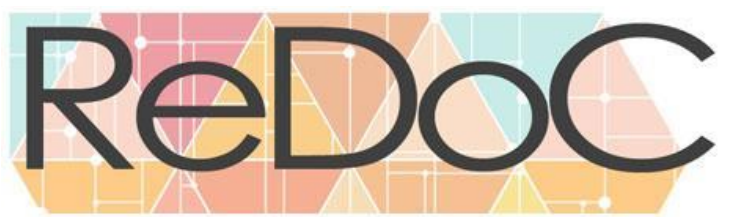

\section{Revista Docência e Cibercultura}

TEIXEIRA, D. A. de O.; NASCIMENTO, F. L. Ensino remoto: o uso do google meet na pandemia da COVID-19. Boletim da Conjuntura, Boa Vista, ano 3, v. 7, n.19, p. 44-61, 2021. Disponível em: http://www.ioles.com.br/boca. Acesso em: 31 jul. 2021.

TINOCA, L.; OLIVEIRA, I. Formative assessment of teachers in the context of an online learning environment. Teachers and Teaching: Theory and Practice, v.19, n. 2, p. 221-234, 2013.

VALE, Leandra Mendes do; Aulas Remotas e as Ferramentas do Google. Portal Eletrônico Fluência Digital [28/08/2020]. Disponível em: https://fluenciadigital.net.br. Acesso em: 31 jul. 2021. que permite uso, distribuição e reprodução para fins não comerciais, com a citação dos autores e da fonte original e sob a mesma licença. 